\title{
EVALUATION OF TRANS-NASAL ENDOSCOPIC CROSS-OVER FLAP TECHNIQUE IN THE REPAIR OF CHOANAL ATRESIA
}

\author{
By
Mohamed Ahmed El-Saeed Ali, Wafaey Abdul Rasol Mohamed and Marwan Ahmed Ibrahim \\ Department of Otorhinolaryngeology, Faculty of Medicine, Al-Azhar University \\ Corresponding author: Mohamed Ahmed El-Saeed Ali, \\ E-mail: moha.mg160@gmail.com
}

\begin{abstract}
Background: Choanal atresia (CA) is a widely recognized craniofacial disorder characterized by the obliteration of the posterior nasal opening, due to the imperforation of the oronasal membrane and overgrowth of the horizontal and vertical process of the palatine bone during weeks 4-11 of the gestation process.
\end{abstract}

Objective: To evaluate the efficacy of trans-nasal endoscopic cross-over flap technique in the repair of choanal atresia with long-term follow-up.

Patients and methods: This study was conducted on 20 choanal atresia cases that were managed by the endoscopic transnasal approach using cross-over flap technique at the Department of Otorhinolaryngology, Bab EL-Sharia and AL-Hussein Hospitals, Faculty of Medicine, AL-Azhar University from December 2018 to January 2020.

Results: The study included 20 cases: 13 females and 7 males, 5 cases were bilateral, 15 cases were unilateral. Four cases were bony atretic plate, and 16 cases were mixed atretic plate. Four cases (20\%) needed post-operative revision repair due to restenosis of the choana. Revision was more common in bilateral cases than unilateral cases and in bony type than mixed type. Also, revision was common in patients with associated malformations, and in patients done before 10 days.

Conclusion: Transnasal endoscopic surgery using cross-over flap technique is one of the best choices in the management of the choanal atresia. Endoscopy and CT are the methods of choice for diagnosis.

Keywords: Trans-nasal endoscopic, Cross-over flap technique, Repair of choanal atresia.

\section{INTRODUCTION}

Neonatal airway obstruction leading to respiratory distress is a fairly common problem in the pediatric ICU setting, and it is important to be able to delineate the characters of the obstruction to be effectively treated it in a timely manner. Bilateral choanal atresia should always be considered in these circumstances, although it is relatively rare as a cause, it is a highly treatable condition. If the atresia is associated with other facial and systemic anomalies, one must consider CHARGE syndrome and other syndromes during the diagnostic process (Flint et al., 2010).

The aetiology is considered to be a persistence of the embryological bucconasal membrane, which separates the nasal cavity from the stomatodeum 
until it breaks down at seventh week of intrauterine development, allowing communication through the primitive posterior nares (Hengerer et al., 2012).

Diagnosis of CA is dependent on high suspicion level. Bilateral atresia is considered as an emergency and presented by bilateral nasal obstruction and cyclic cyanosis that improving when the newborn cries. Unilateral atresia may not be diagnosed for many years and manifesting late as persistent unilateral nasal obstruction and unilateral rhinorrhea, however, some patients may remain asymptomatic. Complementary investigations, such as computerized tomography of facial bone anatomy and nasal endoscopy are essential for diagnosis and therapeutic plane involving localization and differentiation of bone, membrane and mixed atresia (Flint et al., 2010).

Management of this potentially lethal condition includes techniques which have evolved from blind transnasal puncture, trans-palatal exposure, to the currently favored endoscopic transnasal approach using cross-over flap technique. Multiple tools have been employed to repair CA which involves opening and maintaining a patent lumen, including urethral sounds, back-biting forceps, drills, microdebriders and lasers (Yantis et al., 2014).

The use of the endoscope, combining trans-nasal with posterior trans-septal access, enables direct visualization of the surgical field at all angles, even in newborns, with greater surgical precision and safety in bone resections of the posterior part of the septum, atretic plates, and pterygoids, as well as in the fashioning of the mucosal flaps for adequate protection of the raw areas (cross-over flap technique), with minimum trauma to structures in development. These advantages lead to a reduction in the rate of re-stenosis and, consequently, an improvement in success rates (Newman et al., 2013).

In general, unilateral choanal atresia (UCA) is more common than bilateral choanal atresia (BCA) $(65-75 \%$ of patients with unilateral), and females are more likely to have it (2:1 ratio to males). Unilateral choanal atresia is most commonly occurs on the right side, and if it is bilateral, there is a high correlation with syndromic illnesses such as CHARGE syndrome, Treacher Collins, and Crouzon's disease (75\% of cases) (Yantis et al., 2014).

The aim of this study was to evaluate the efficacy of trans-nasal endoscopic cross-over flap technique in repair of congenital choanal atresia with long-term follow-up.

\section{PATIENTS AND METHODS}

This study was conducted on 20 patients with choanal atresia that were managed by endoscopic transnasal approach using cross-over flap technique at the Department of Otorhinolaryngology, Bab EL-Sharia and AL-Hussein Hospitals, Faculty of Medicine, AL-Azhar University from December 2018 to January 2020.

The study included 20 cases: 13 females and 7 males, 5 cases were bilateral and 15 cases were unilateral. Also, 4 cases were bony atretic plate and 16 cases were mixed atretic plate. 
Diagnosis and preoperative evaluation:

- In BCA cases, the preliminary diagnosis was done by the neonatologist at the time of birth based on the clinical finding of cyclic respiratory obstruction that was relieved by crying or by placement of an oropharyngeal airway. The diagnosis was supported by failure of introducing a small French catheter sized (No.6) through the nose into the nasopharynx.

- In UCA cases, the diagnosis was depending on persistent unilateral rhinorrhea and unilateral nasal

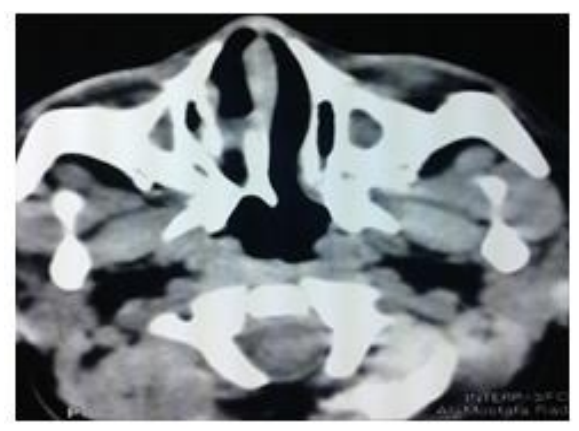

Figure (1): CT of bony type UCA

- Physical examination to assess the patient's general condition and to exclude any other associated congenital anomalies was done.

- Complete preoperative routine laboratory investigations and cardiac evaluation including chest X-ray and echocardiography were also performed prior to surgery.

- All neonates with BCA were kept in the neonatal intensive care unit (NICU) on an oropharyngeal airway to secure respiration and an orogastric tube to maintain adequate feeding until the time of surgery. obstruction.

- Careful history and complete otorhinolaryngological examination including endoscopic nasal examination was performed in all cases to establish the diagnosis.

- Preoperative multi slice CT scans was done for all cases to confirm the diagnosis as well as to evaluate the extent and nature of the atresia (Figure 1, 2).

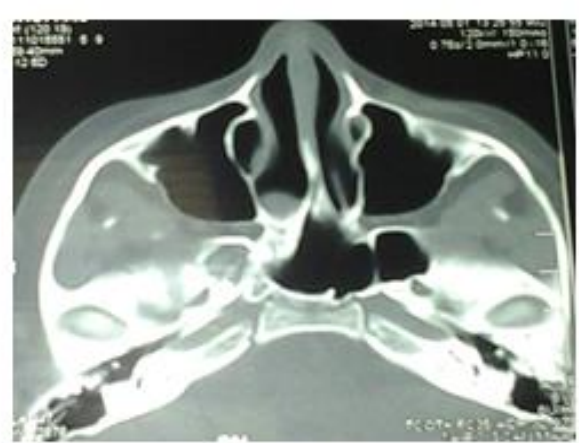

Figure (2): CT of mixed type BCA

\section{Surgical technique:}

The surgical procedure for CA cases was performed using nasal endoscope (endoscope 0 with diameter 2,7 or $4 \mathrm{~mm}$ ), and powered instruments (micro drill and micro debrider).

After general anesthesia and oral endotracheal intubation, a moist gauze pack was placed in the nasopharynx to displace the soft palate caudally away from the atretic plate. It also acted as a protection for the posterior pharyngeal wall and the eustachian tube orifices.

- The nasal mucosa was packed with cotton soaked in adrenalin 1:100,000 and topical vasoconstrictive solution 
for 5-7 min before staring surgery to decrease blood loss and shrink the turbinates.

- Using a 4-mm $0^{\circ}$ endoscope, the site of the atresia plate was subperiosteally infiltrated. Using a microsurgical scalpel, $1.5 \mathrm{~cm}$ from the atretic plate, an "L"-shaped incision was made through the mucoperiosteum of the septum, following to the floor of the nasal cavity, reaching the lateral wall of the nose, The mucoperiosteum was then elevated, creating a flap that remains pedicled with its vascular supply on the roof, and upper posterior and lateral nasal walls. This flap was carefully manipulated because it provided the cover for the roof and superior borders of the new open choana (superior flap of the cross-over flap technique).

- The bony plate was then visualized and removed by diamond drill, and continuing with a modified microKerrison punch to complete the removal.

- The membranous atelectic plate was widened by microdeprider.

- Next, the bony portion of the posterior septum was removed (utilizing a backbiting forceps or micro-Kerrison punch). This removal was performed similarly to a classic septoplasty of the vomer region. It created a larger than normal opening, and be done very carefully, preserving the mucosa that covered the contralateral side of the nasal septum. This mucosa served as the flap that covered the floor and borders of the new choana. At this point, an inverted "L"-shaped incision was made around the free mucosa, in its anterior and superior borders, creating an inferior nasal septum flap (the inferior flap of the cross-over technique).

- The perforation formed was carefully enlarged under vision there by allowing identification of the Eustachian tube orifice thus preventing its damage during manipulation.

- The drill was needed to be kept away from the end of the endoscope at all times.

- In some patients the posterior part of the nasal septum was gently excised starting from the osteo-chondral junction in a posterior direction, Adequate resection of the vomer and the atretic plate over the pterygoid processes was essential to create a large neo-choana thus preventing restenosis and forming a wide neo-unichoana"choanoplasty"'(Figure 3). 


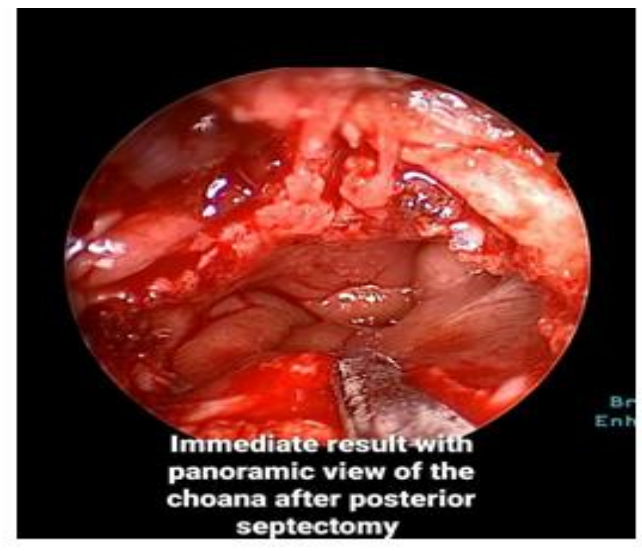

Figure (3): Panoramic view of the new choana.

- At the end of the surgical procedure, repeated saline nasal irrigation was used to wash out any bony fragments that could cause postoperative nasal debris and crust formation.

- Stent was used in some cases with CA using endotracheal tube $(3,5)$ or folly catheter for 3-6 weeks.

\section{Postoperative care:}

The neonates with BCA were returned back to the NICU following surgery and were discharged after 3 days if free from postoperative complications. The older patients with unilateral atresia were returned pack to the inpatient department and were discharged after 2 days if there were no complications such as bleeding, difficulty in breathing, or difficulty in feeding.

They all received a prophylactic intravenous antibiotic for 72-hrs postoperatively with dosage according to their body weight. Local steroids and antibiotics were prescribed intranasal until the stent is removed (within 6 weeks).

Before hospital discharge, parents were taught how to irrigate and clean both nasal cavities using frequent saline nasal drops and a suction pump device and avoid deep suction to prevent injury to mucosa of neo-choana to prevent restenosis.

Patients were followed-up for a period of at least 6 month after surgery. Patients were followed up every week for 3 month and every two weeks for the next 3 month then every month.

At follow-up visits, nasal breathing was assessed and the nose examined with an endoscope if the child was symptomatic. Sedation was sometimes necessary in some children for examination.

During the postoperative follow-up period, any granulations or crusts found were removed and debridement was performed until complete healing was achieved.

Surgery was considered successful if the patient showed bilateral normal nasal breathing with no evidence of airway obstruction during feeding or at rest.

Stent was removed after 6 weeks. Some cases needed general anesthesia for removal of the stent and to exclude restenosis and granulation tissues (Figure 4). 


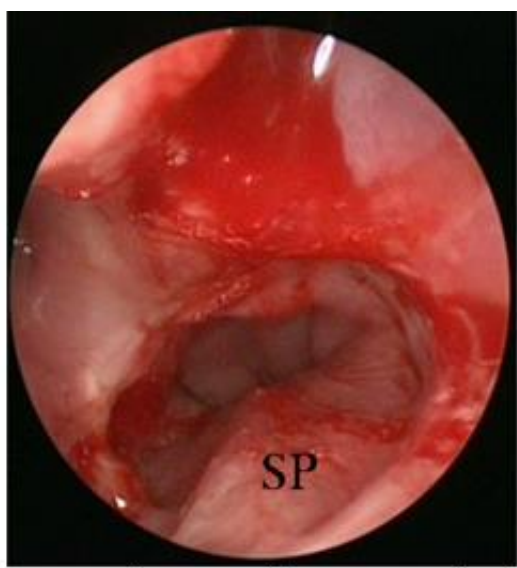

Figure (4): new choana after removal of the stent.

\section{Statistical analysis}

Analysis of data was done using Statistical Program for the Social Science version 20 (SPSS Inc., Chicago, IL, USA). Quantitative variables were described in the form of mean and standard deviation. Qualitative variables were described as number and percent. In order to compare parametric quantitative variables between two groups, Student $t$ test was performed or mann-whitney test. Qualitative variables were compared using chi-square (X2) test or Fisher's exact test when frequencies were below five. Pearson correlation coefficients were used to assess the association between two normally distributed variables. $\mathrm{P}$ value < 0.05 was considered significant.

\section{RESULTS}

The study included 20 cases: 13 females and 7 males. The atretic plate was bilateral in 5 cases $(25 \%)$ and unilateral in 15 cases $(75 \%)$ with 10 cases in RT side and 5 cases in LT side. The most common atretic plate was mixed type 16 cases $(80 \%)$ and 4 cases (20\%) of pure bony type. All bilateral cases (5 cases) were diagnosed at birth (first day) and unilateral cases (15) were diagnosed at the 4th month to 20 years. Four cases of the total (20\%) presented associated malformations with the most common syndrome was CHARGE syndrome ( 2 cases $10 \%$ ) then down syndrome (1 case $5 \%$ ), and other associated malformations included heart disease (1 case 5\%). The associated malformations were common in bilateral cases.

Four patients with bilateral choanal atresia needed stabilization of air way prior to surgery by McGovern nipple in (20\%) and 1 case needed endotracheal intubation (5\%), and patients with unilateral choanal atresia (15 cases $75 \%$ ) were stable and needed nothing. In our study, 5 patients $(3$ bilateral and 2 unilateral) needed stent insertion for 6 weeks, while the remaining 15 patients (2 bilateral and 13 unilateral) did not need stent (Table 1). 
Table (1): Criteriae of the patients

\begin{tabular}{|c|c|c|c|}
\hline \multicolumn{2}{|r|}{ Variables } & Number & Percent \\
\hline \multirow{2}{*}{ Gender } & Male & 7 & $35 \%$ \\
\hline & Female & 13 & $65 \%$ \\
\hline \multirow[b]{2}{*}{ Site of atresia } & \begin{tabular}{|l} 
Unilateral \\
\end{tabular} & 15 & $75 \%$ \\
\hline & \begin{tabular}{|l} 
Bilateral \\
\end{tabular} & 5 & $25 \%$ \\
\hline \multirow{2}{*}{$\begin{array}{l}\text { Side of unilateral } \\
\text { atresia }\end{array}$} & Right & 10 & $66.7 \%$ \\
\hline & Left & 5 & $33.3 \%$ \\
\hline \multirow{2}{*}{$\begin{array}{c}\text { Type of atretic } \\
\text { plate }\end{array}$} & Bony & 4 & $20 \%$ \\
\hline & Mixed & 16 & $80 \%$ \\
\hline \multirow{2}{*}{ Date of diagnosis } & First day & 5 (bilateral) & $25 \%$ \\
\hline & Years ago & 15(unilateral) & $75 \%$ \\
\hline \multirow{2}{*}{$\begin{array}{c}\text { Associated } \\
\text { malformations }\end{array}$} & No (CA alone) & 16 & $80.0 \%$ \\
\hline & \begin{tabular}{|l} 
Yes (CA with malformations) \\
\end{tabular} & 4 & $20.0 \%$ \\
\hline \multirow{3}{*}{$\begin{array}{c}\text { Types of } \\
\text { malformations }\end{array}$} & Charge syndrome & 2 & $10.0 \%$ \\
\hline & Down syndrome & 1 & $5.0 \%$ \\
\hline & Heart disease & 1 & $5.0 \%$ \\
\hline \multirow{3}{*}{$\begin{array}{c}\text { Stabilization of } \\
\text { airway prior to } \\
\text { surgery }\end{array}$} & \begin{tabular}{|l} 
(Unilateral cases ) nothing \\
\end{tabular} & 15 & $75.0 \%$ \\
\hline & $\begin{array}{l}\text { (Bilateral cases) needed } \\
\text { McGovern nipple }\end{array}$ & 4 & $20.0 \%$ \\
\hline & $\begin{array}{l}\text { (Bilateral cases) endotracheal } \\
\text { intubation }\end{array}$ & 1 & $5.0 \%$ \\
\hline
\end{tabular}

All the patients had been discharged from hospital in a duration ranging from 3 to 14 days with the mean is 6.7 days (Table 2).

Table (2): Duration of hospital stay (days)

\begin{tabular}{|l|c|c|c|c|c|c|}
\hline & N & Minimum & Maximum & Median & Mean & SD \\
\hline Duration of hospital stay (days) & 20 & 3.00 & 14.00 & 7.00 & 6.70 & 3.5 \\
\hline
\end{tabular}

Seven of the total patients $(35 \%)$ had postoperative complications, these complications were, restenosis (4 cases $57.1 \%$ ), septoturbinate synechia (2 cases
28.6\%), and columella pressure necrosis ( 1 cases $14.3 \%)$. Four cases $(20 \%)$ of restenosis required post-operative revision repair (Table 3 ).

Table (3): Complications and post-operative revision

\begin{tabular}{|c|l|c|c|}
\hline & & Number & Percent \\
\hline \multirow{2}{*}{$\begin{array}{c}\text { Post-operative } \\
\text { complications }\end{array}$} & No & 13 & $65 \%$ \\
\cline { 2 - 4 } & Yes & 7 & $35 \%$ \\
\hline \multirow{3}{*}{ Types of complications } & Restenosis & 4 & $57.1 \%$ \\
\cline { 2 - 4 } & Septoturbinate synnechia & 2 & $28.6 \%$ \\
\cline { 2 - 4 } & Columella pressure necrosis & 1 & $14.3 \%$ \\
\hline \multirow{2}{*}{ Post-operative revision } & Doesn't need & 16 & $80 \%$ \\
\cline { 2 - 4 } & Need & 4 & $20 \%$ \\
\hline
\end{tabular}


Revision was more common in bilateral cases than unilateral cases, in bony type than mixed type, in patients with associated malformations, and in patients done before 10 days (Table 4).

Table (4): Patients who required post-operative revision

\begin{tabular}{|l|c|}
\hline Total patient & Patient required revision \\
\hline Laterality: & $\mathbf{2 ( 1 3 . 3 \% )}$ \\
$>$ Unilateral (15) & $\mathbf{2 ( 4 0 \% )}$ \\
$>$ Bilateral (5) & $\mathbf{2 ( 5 0 \% )}$ \\
\hline Type of plate & $\mathbf{2 ( 1 2 . 5 \% )}$ \\
$>$ Bony (4) & \\
$>$ Mixed(16) & $\mathbf{1 ( 5 0 \% )}$ \\
\hline Age of patient at time of repair & $\mathbf{3 ( 1 6 . 7 \% )}$ \\
$>$ Less than 10 dyes $(2)$ & More than 10 dyes $(18)$ \\
\hline
\end{tabular}

\section{DISCUSSION}

In our study, $65 \%$ of patients were female and $35 \%$ were male, and UCA was the most frequent $(75 \%)$. The plates were mixed in most cases $(80 \%)$ and bony to a lesser extent $(20 \%)$.

Historically, the anatomical classification of CA was commonly quoted for decades as $90 \%$ bony and $10 \%$ membranous (Newman et al., 2013).

However, a more modern analysis using CT scan studies by Zanetta et al. (2012) showed that CA is purely bony in $30 \%$ of cases and mixed bonymembranous in $70 \%$, with no pure membranous anomalies found. This classification was proved in all next studies (El-Ahl and El-Anwar, 2012).

We similarly did not find any pure membranous atresia accessible to rupture and dilatation among our cases. We found that $80 \%$ of our CA cases had mixed bony-membranous atretic plates and $20 \%$ had pure bony atretic plate.

Depending on the type of atresia and age of the patient, the symptoms vary from mild respiratory distress with feeding to severe airway obstruction.

Neonates with BCA have immediate cyclic cyanosis which can be relieved with crying. These cases require immediate stabilization of the airway and feeding through an orogastric tube, and urgent airway intervention, like oral airway or intubation or McGovern nipple because the neonates are obligate nasal breathers (Zuckerman et al., 2010).

Unilateral cases tend to appear between 5 and 24 months after birth, sometimes the diagnosis takes place late during childhood or adolescence, manifesting as nasal obstruction and positional unilateral rhinorrhea (increases by tilting the head forward), and occasionally as unilateral otitis media (Ramsden et al., 2011).

Patients with CA should be studied to identify and treat possible associated malformations (present in $20 \%$ to $50 \%$ of cases), like CHARGE syndrome (Velegrakis et al., 2013).

In our study, $20 \%$ of our patients presented with other associated anomalies, especially those with BCA. 
Most common syndrome was CHARGE syndrome, followed by Down syndrome, and then associated heart diseases.

Patients with BCA require stabilization of the airway, which can be achieved using a McGovern nipple, oral cannula or endotracheal intubation. Tracheostomy is reserved for situations in which other craniofacial anomalies are associated. The definitive treatment is surgical and is recommended in the first days of life in bilateral cases, although it can be delayed if the CA is unilateral and no serious respiratory or feeding problems exist (Saleem et al., 2010).

In our study, patients with BCA needed stabilization of air way prior to surgery by McGovern nipple in 20\%, and endotracheal intubation in $5 \%$, and patients with UCA $(75 \%)$ were stable and needed nothing.

Some authors prefer surgical correction of UCA from 12 months of age. The rationale for this delayed repair is allowing the nasal cavity to become larger, and also so the surgically created choanal opening does not grow along the surrounding tissues, becoming narrower when the child matures (Saleem et al., 2010).

In our study, a total of $25 \%$ of patients with BCA underwent interventions within the first month, and $75 \%$ with UCA were operated after 4 years.

Different techniques for the surgical correction of CA have been described, with the transnasal, transpalatal and transseptal approaches. In recent years, the intranasal route has displaced the classical palatal pathway, as it is less invasive and provides excellent results (Kim et al., 2012).

In our study, we put stent in some patients; the duration of nasal stent range was 6 weeks. The use of stent entails certain risks, including damage to the nasal mucosa by excessive pressure, resulting in granulation tissue and scar formation, bacterial overgrowth and blocking of mucus drainage (Saafan, 2013).

The placement of a stent made with soft material for a short time reduces the possibility of formation of granulation tissue and the risk of postoperative infection, thus reducing the risk of choanal restenosis (Zanetta et al., 2012).

Varying amount of granulation could be formed in relation to stent at the edge of neochoana that need to be removed later. So it is preferred by many surgeons not to use nasal stent (Ibrahim et al., 2010).

Total of $35 \%$ cases had postoperative complications which were attributed to nasal stent, such as restenosis $(57.1 \%)$, septoturbinate synechia (2 cases $28.6 \%$ ) and columella pressure necrosis $(14.3 \%)$.

Our success rate for unilateral cases was $86.6 \%$, while for bilateral cases it was lower, 60\%. This may have occurred because children with bilateral atresia were operated on earlier, mostly before 6 months of age. The re-stenosis cases were treated by the same surgical technique, with enlargement of the new choana by removing a larger portion of the posterior nasal septum.

In the current study, we have found that the use of postoperative home saline irrigation and suction of the nasal cavities 
by a suction pump after proper training is extremely beneficial. This maneuver aimed to maintain the nasal cavities continuously free from debris and crusts during the first 2-3 weeks following surgery. This may have a role in decreasing the chances for infection and granulation tissue formation and thus restenosis. The parents were cautioned not to use the suction catheters aiming for suction to avoid injury of folded mucosa of neo-choana, but rather to gently suction-out secretions and debris using a suction pump to maintain patency of the nasal passage. There is no doubt that this care is much easier in cases without stent.

In our study $20 \%$ need post-operative revision repair due to restenosis of the choana, revision more common in bilateral cases $40 \%$ than unilateral one $(13.3 \%)$, in bony type $50 \%$ than mixed type $(12.5 \%)$, in patient with associated malformations, and in patient done before 10 days.

The need for revision documented in the literature varies widely from $10.2 \%$ to $89 \%$. This is because the term "revision" is defined differently by different authors. Some consider revision as the additional removal of tissue, whilst others define it as any procedure under general anaesthesia subsequent to surgery, including the removal of a nasal stent (Velegrakis et al., 2013).

Predictive factors of restenosis include age less than 10 days (due to the normally narrow noses of newborns, and limited resection of the vomer), and insufficient postoperative endoscopic control (Kim et al., 2012).

\section{CONCLUSION}

Endoscopy and CT are the methods of choice for diagnosis. Transnasal endoscopic surgeries utilizing the 0 and $45^{\circ}$ endoscopes are the techniques of choice in the treatment of the CA. Endoscopic transnasal surgery utilizing mucoperiosteum pedicled flaps with removal of the posterior osseous nasal septum diminished the incidence of restenosis.

\section{REFERENCES}

1. El-Ahl MA and El-Anwar MW. (2012): Stentless endoscopic transnasal repair of bilateral choanal atresia starting with resection of vomer. Int J Pediatric Otorhinolaryngology, 76:1002-6.

2. Flint PW, Haughey BH, Lund VJ, Niparko JK and Richardson MA. (2010): Cummings Otolaryngology Head and Neck Surgery. 5th. 1-2. Pbl. Philadelphia: Elsevier, Pp. 2694-2695.

3. Hengerer AS, Brickman TM and Jeyakumar A. (2012): Choanal atresia: embryologic analysis and evolution of treatment, a 30-year experience. Laryngoscope, 118(5):862-866.

4. Ibrahim AA, EA Magdy and MH Hassab. (2010): Endoscopic Choanoplasty without Stenting for Congenital Choanal Atresia Repair. Internation Journal of Pediatric Otorhinolaryngology, 74: 144-150.

5. Kim H, Park JH, Chung H, Han DH, Kim DY and Lee CH. (2012): Clinical features and surgical outcomes of congenital choanal atresia: factors influencing success from 20 year review in an institute. Am J Otolaryngol., 33:308-12.

6. Newman JR, Harmon P, Shirley WP, Hill JS, Woolley AL and Wiatrak BJ. (2013): Operative management of choanal atresia: a 15-year experience. JAMA Otolaryngol Head Neck Surg., 139:71-5.

7. Ramsden JD, Campisi $P$ and Forte V. (2011): Choanal atresia and choanal stenosis. Otolaryngol Clin North Am., 42: 339---52. 
8. Saafan ME. (2013): Endoscopic management of congenital bilateral Posterior choanal atresia: value of using stents. Eur Arch Otorhinolaryngol., 270:129-34.

9. Saleem AF, Ariff S, Aslam $N$ and Ikram M. (2010): Congenital bilateral choanal atresia. J Pak Med Assoc., 60: 869-72.

10. Velegrakis S, Mantsopoulos K, Iro $H$ and Zenk J. (2013): Long-term outcomes of endonasal surgery for choanal atresia: 28 years' experience in an academic medical centre. Eur Arch Otorhinolaryngology, 270:113-6.
11. Yantis M, Mukerji S and Mukerji SD. (2014): Diagnosis, Management, and Association with CHARGE Syndrome. J Pak Med Assoc., 13: 53-58.

12. Zanetta A, Rodriguez H, Quiroga V, Cuestas G and Tiscornia C. (2012): Congenital nasal obstruction due to choanal atresia. Arch Argent Pediatr., 110:152---5.

13.Zuckerman JD, Zapata S and Sobol SE. (2010): Single-stage choanal atresia repair in the neonate. Arch Otolaryngol Head Neck Surg., 134: 1090-1093. 


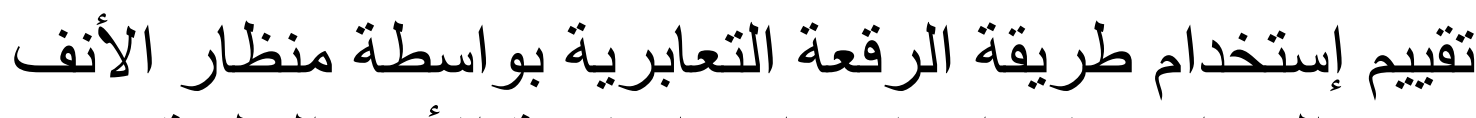
الجراحى فى إصلاح إنسداد فتحة الأنف الخلفية الخدية محمد أحمد السعيد على، وفائى عبد الرسول محمد، مروان أحمد إبراهيم قسم الأنن والأفف والحنجرة، كلية الطب، جامعة الأزهر

E-mail: moha.mg160@gmail.com

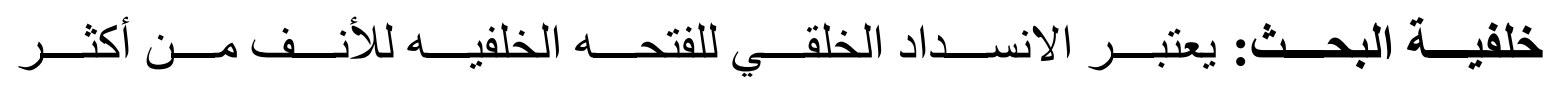

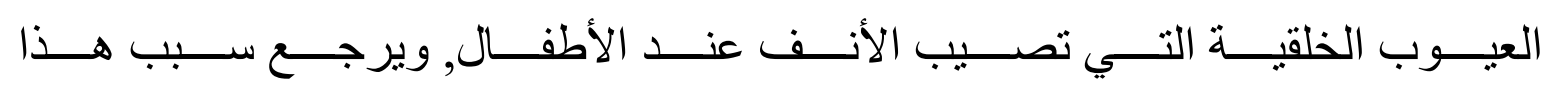

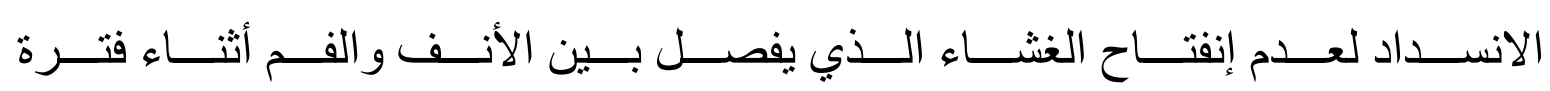
الحمل من الاسبوع الرابع الى الاسبوع الحادي عشر.

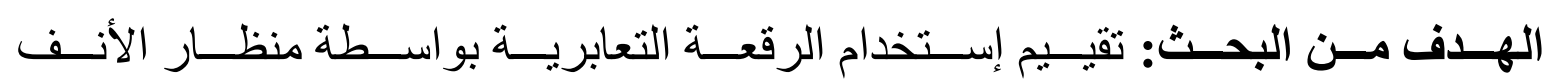
الجر احى فى إصلاح إنسداد فتجة الأنف الخلفية.

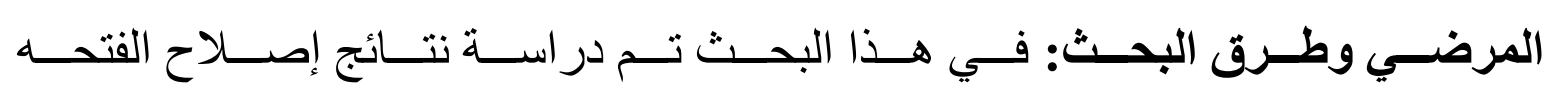

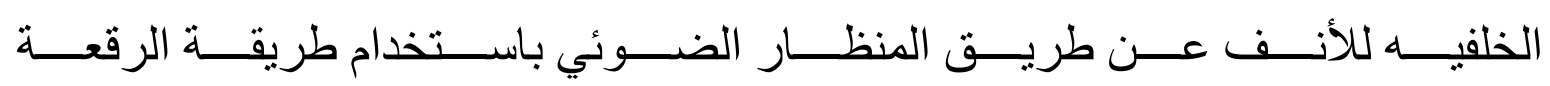

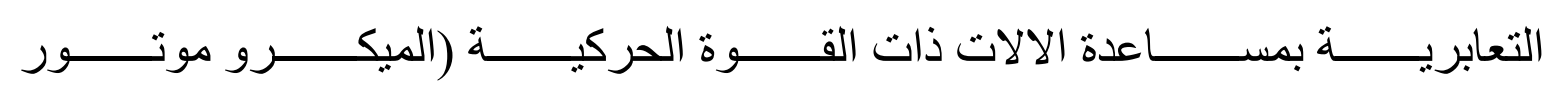

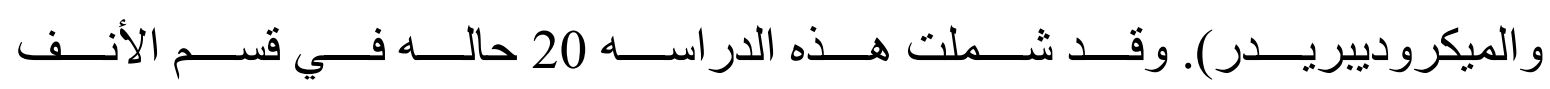

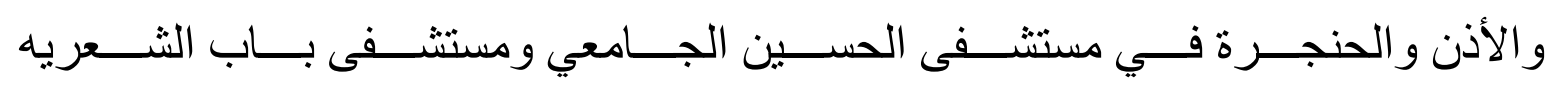

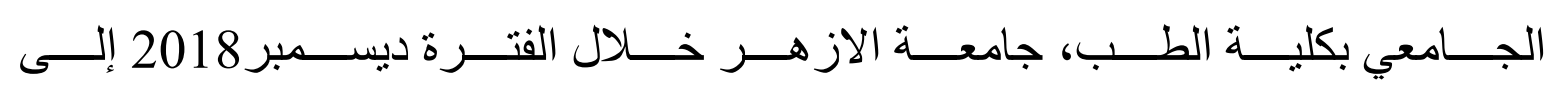

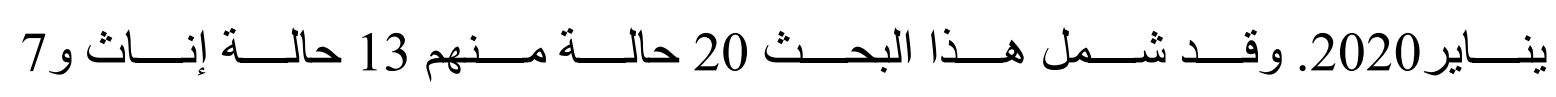

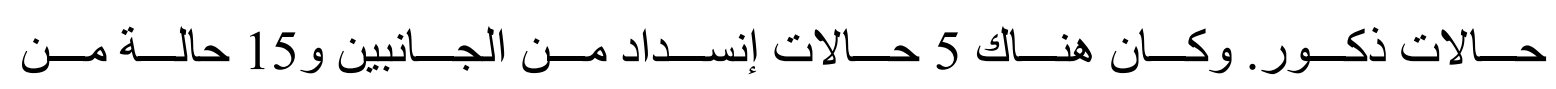

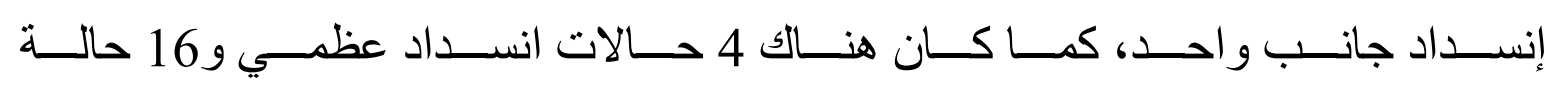
مختلط عظمي و غشائي.

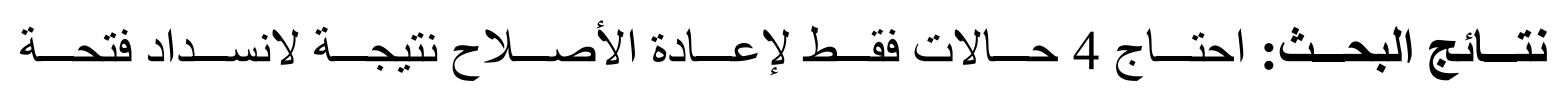

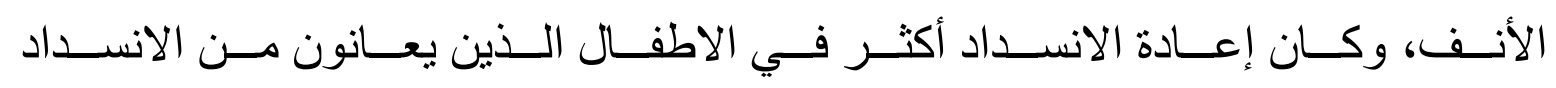




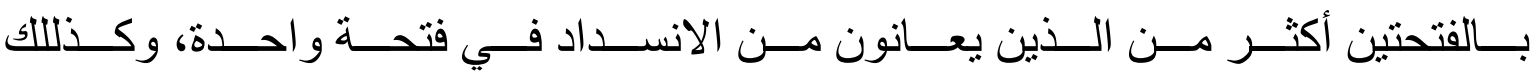

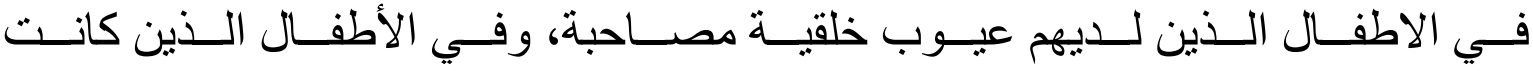
أعمار هم اقل من أسبو عين أثناء عملية إصلاح فتحة الانف.

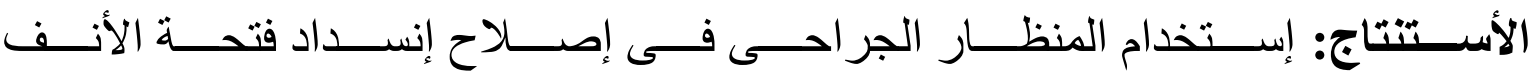

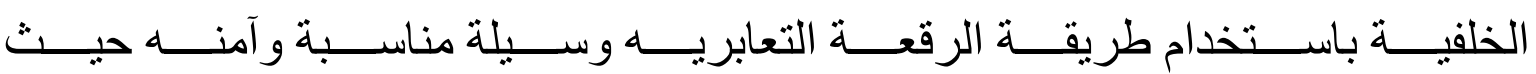

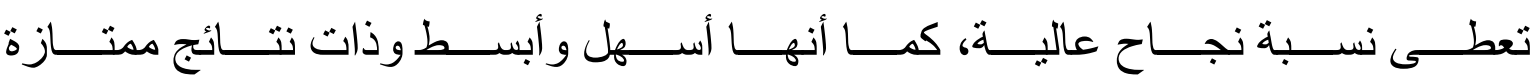
ونسبة حدوث المضاعفات ضئيلة جدا.

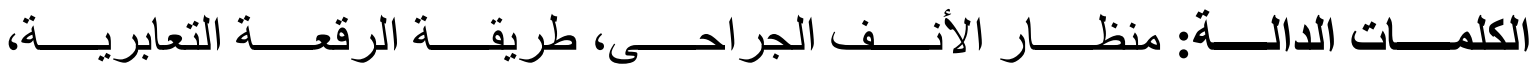
إصلاح انسداد فتحة الانف الخلفية. 